\title{
PRODUÇÃO DE BIODIESEL A PARTIR DE ÓLEO DE SOJA E ETANOL POR REAÇÃO ASSISTIDA EM ULTRASSOM
}

\author{
M.A. PRADO ${ }^{1}$, F. HAMERSKI ${ }^{2}$, A. ZANDONÁ2 ${ }^{2}$, L.P. RAMOS ${ }^{3}$ e M.L. CORAZZA ${ }^{2}$ \\ ${ }^{1}$ Universidade Federal do Paraná, Mestrando do Programa de Pós Graduação do \\ Departamento de Engenharia Química \\ ${ }^{2}$ Universidade Federal do Paraná, Departamento de Engenharia Química \\ ${ }^{3}$ Universidade Federal do Paraná, Departamento de Química \\ E-mail para contato: corazza@ufpr.br
}

\begin{abstract}
RESUMO - O objetivo deste trabalho foi avaliar a cinética e a conversão global de processo assistido por ultrassom para produção de ésteres etílicos de soja. Nas reações utilizou-se $\mathrm{KOH}$ como catalisador, temperaturas ambiente e $55^{\circ} \mathrm{C}$ e razão molar álcool:óleo fixada em 9:1 e vazões de 0,4 e 0,8 L.min ${ }^{-1}$ em sistema em escala semi-piloto, com capacidade de $7 \mathrm{~L}$ de operação. A quantificação dos ésteres obtidos foi realizada em um CG com um detector FID. Os ésteres produzidos foram purificados por lavagem e filtrados com sulfato de sódio anidro. A partir dos resultados obtidos observou-se que este processo de transesterificação em ésteres etílicos foi acelerado pela irradiação de ultrassom em tempos de reação relativamente curtos, quando comparados com o processo convencional. A partir dos resultados obtidos no presente trabalho tem-se uma perspectiva promissora para a obtenção de biodiesel em reações assistidas por ultrassom em escala piloto.
\end{abstract}

\section{INTRODUÇÃO}

Nas últimas décadas, o uso de óleos vegetais como fonte de energia tem se tornado uma alternativa em potencial para substituir ou até complementar uma importante fração dos combustíveis derivados do petróleo. Esta possibilidade é conhecida desde o início dos motores diesel (PAIVA, 2010).

Criado por Rudolf Diesel o primeiro modelo do motor a diesel que funcionou de forma eficiente, foi apresentado durante a Exposição Mundial de Paris, em 1900. Motor o qual funcionou com óleo de amendoim (KNOTHE et al., 2006). Após sua morte, a indústria do petróleo criou um tipo de óleo que denominou de "Óleo Diesel". Sendo mais barato que os demais combustíveis, passou a ser largamente utilizado. Sua abundância aliada aos baixos custos dos seus derivados fez com que o uso dos óleos vegetais caísse no esquecimento (BIODIESELBR, 2013).

Das matrizes energéticas mundiais, segundo International Energy Agency (IEA), apenas 13,2 $\%$ são oriundas de fontes renováveis. Enquanto 86,8 \% são de matrizes não renováveis (Figura 1 à esquerda). O balanço energético nacional, do Ministério de Minas e Energia (MME), mostra que $44,2 \%$ da matriz energética brasileira utilizada é de fonte renovável, em contraste com a mundial 
de $13,2 \%$. Mas ainda assim é amplamente utilizado petróleo e seus derivados que compreendem $38,6 \%$ (Figura 1 à direita).
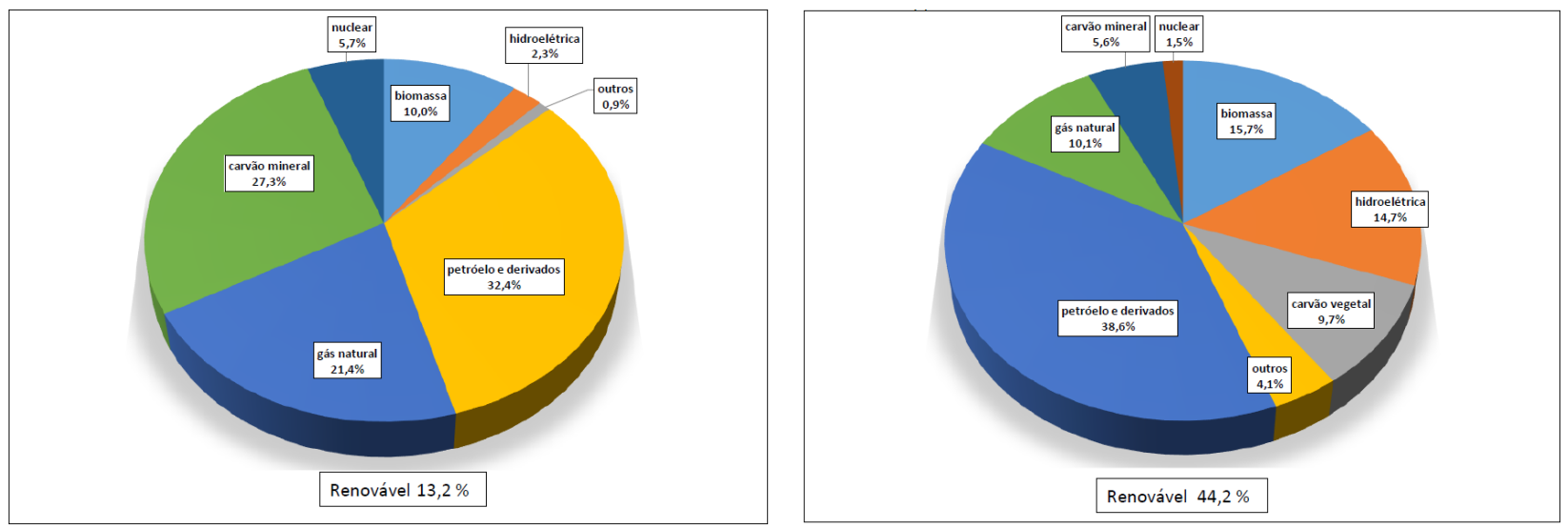

Figura 1. A esquerda Matriz Energética Mundial, (Key World Statistics, 2012), e a direita Matriz Energética Brasileira, (Balanço Energético Nacional, 2012)

A possibilidade da escassez e até esgotamento dessas fontes não renováveis, podem se tornar o principal problema para o desenvolvimento dos países, além de serem agentes poluidores por gases nitrogenados e dióxido de carbono. Desse modo, é importante buscar alternativas para os problemas decorrentes da utilização do petróleo como fonte de energia. Uma alternativa é a utilização de Biodiesel que é um combustível derivado de fontes renováveis, que pode ser obtido por diferentes processos tais como o craqueamento, a esterificação ou pela transesterificação (BORESTEIN 2008).

Para que um óleo possa ser transesterificado é necessária a presença de um catalisador, podendo ser uma base, um ácido ou uma enzima. Representada pela equação geral estequiométrica mostrada na Figura 2 (VLADA et al., 2012), sendo 1 mol de óleo para 3 mols de qualquer álcool, com catalisador resultando em 3 mols de uma mistura de éster mais 1 mol de glicerol.

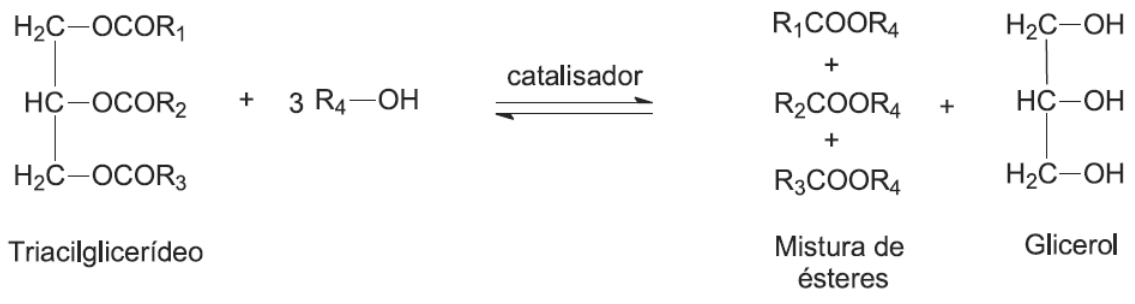

Figura 2. Equação geral estequiométrica de transesterificação.

No presente trabalho, o óleo de soja foi selecionado como matéria prima para a produção de ésteres etílicos (biodiesel). Pois é o óleo com maior potencial para atender a demanda por biodiesel (PINTO et al., 2005) e representa cerca de $80 \%$ de sua produção. 
Como poucos são os trabalhos que têm estudado esta reação com uma planta semi-piloto, o objetivo principal deste trabalho foi avaliar a cinética e a conversão do processo assistido por ultrassom para produzir biodiesel etílico de soja em meio a uma reação alcalina catalisada por hidróxido de potássio $(\mathrm{KOH})$. A unidade de ultrassom utilizado para auxiliar na catálise da reação busca uma diminuição do tempo de conversão do óleo em ácidos graxos de ésteres etílicos (FAEE).

\section{MATERIAIS E MÉTODOS}

O óleo de soja refinado utilizado foi obtido da empresa IMCOPA. Os componentes hidróxido de potássio (KOH, grau 87,54\%, NÉON), etanol anidro (grau 99,5\% Itajá) foram utilizados conforme recebidos. Padrões como palmitato de etila, oleato de etila, linoleato de etila, linolenato de etila e estearato de etila (Sigma-Aldrich). A Figura 3 apresenta todo o precesso de produção, separação e purificação dos ésteres obtidos. O reator de ultrassom utilizado (Biominas), com uma frequência de $20 \mathrm{kHz}$ e uma potência de $600 \mathrm{~W}$, com vaso de aplicação de ultrassom com volume de 1 Le um vaso de mistura de 7 L, apresentado na Figura 4 (direita). Ainda, na Figura 4 (esquerda), é apresentado um diagrama esquemático da unidade montada e utilizada para a produção de éster etílico de soja por irradiação de ultrassom.

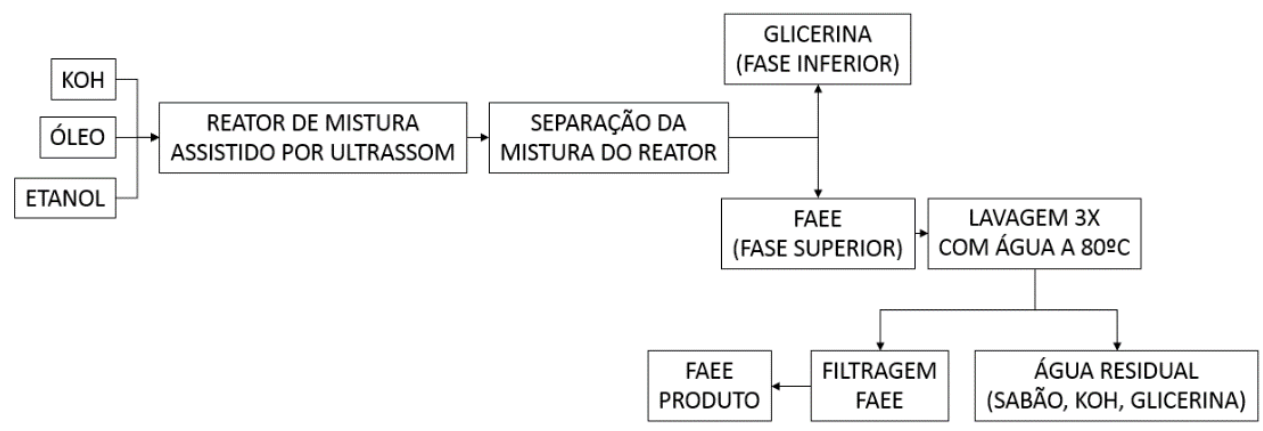

Figura 3. Fluxograma do processo usado para a produção de biodiesel etílico de soja.

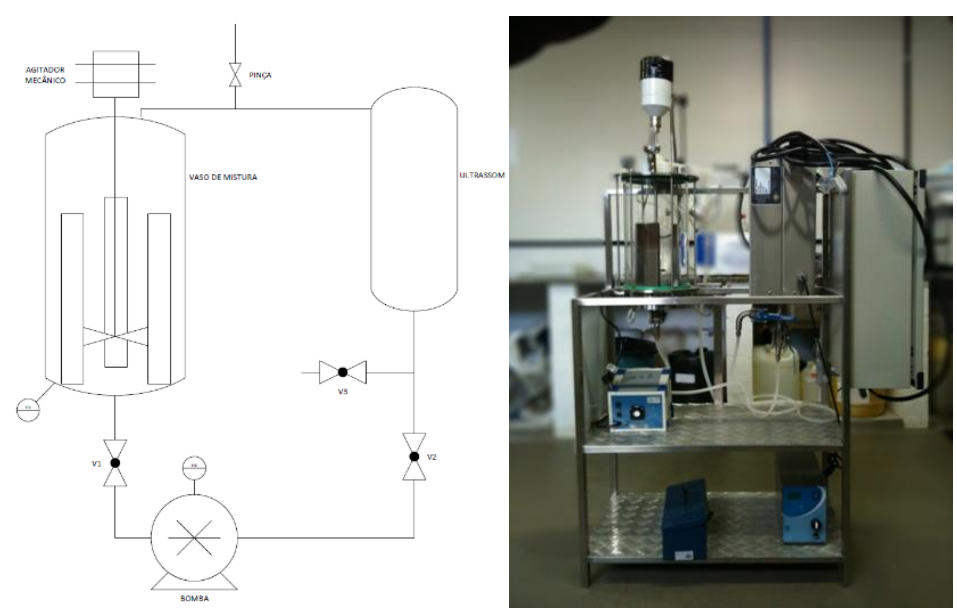

Figura 4. Fluxograma do processo à direita e uma imagem do reator à esquerda. 


\section{9 a 22 de outubro de 2014 \\ Florianópolis/SC}

A quantificação de ésteres metílicos e etílicos de ácidos graxos provenientes de matériasprimas oleosas foi realizada de acordo com a norma EN 14105 utilizando-se cromatografia em fase gasosa (Thermo-Trace 1310) com injetor split/split-less (modo PTV), detector de ionização de chama (FID) e sistema de processamento de dados ChromQuest 5.0. A coluna utilizada foi uma Select Biodiesel para acilgliceróis (CP9080) com $30 \mathrm{~m}$ x 0,25 mm x 0,25 $\mu \mathrm{m}$ e temperaturas no detector de $420{ }^{\circ} \mathrm{C}$. A rampa de aquecimento para o injetor foi de 70 a $100{ }^{\circ} \mathrm{C}$ com taxa de aquecimento de $5^{\circ} \mathrm{C} / \mathrm{s}$; tempo de espera de 2 min e aquecimento para $410^{\circ} \mathrm{C} \mathrm{com} \mathrm{taxa} \mathrm{de} 10^{\circ} \mathrm{C} / \mathrm{s}$ e tempo de espera de 28 minutos. Na coluna, o aquecimento inicial foi de $90^{\circ} \mathrm{C}$, elevado para 150 ${ }^{\circ} \mathrm{C}$ com taxa de aquecimento de $4{ }^{\circ} \mathrm{C} / \mathrm{s}$, com tempo de espera de $0,5 \mathrm{~min}$; elevada para $190{ }^{\circ} \mathrm{C}$ com taxa de aquecimento de $7^{\circ} \mathrm{C} / \mathrm{s}$ e tempo de espera de $0,5 \mathrm{~min}$. Em seguida, elevada para $220^{\circ} \mathrm{C}$ com taxa de aquecimento de $10^{\circ} \mathrm{C} / \mathrm{s}$ e tempo de espera de 0,5 minutos. E, finalmente elevada para 350 ${ }^{\circ} \mathrm{C}$ com taxa de aquecimento de $40^{\circ} \mathrm{C} / \mathrm{s}$ e tempo de espera de $2 \mathrm{~min}$. O volume de amostra injetada foi de 1,5 $\mu \mathrm{L}$ e os gases utilizados foram: ar sintético e hidrogênio em razão de 10:1 (v/v) e nitrogênio como gás de arraste $(0,8 \mathrm{~mL} / \mathrm{min})$ em modo split de 1:10. Para a quantificação foram utilizados os métodos de normalização de área e de padronização externa, quando da disponibilidade de padrões verdadeiros.

\subsection{Procedimento para os experimentos cinéticos}

Foram realizados testes inicias com base na literatura para se adequar e definir as condições dos experimentos cinéticos. Thanh et al., (2010) utilizou um sistema semelhante ao proposto, com metanol e óleo de canola. Estes pesquisadores utilizaram várias razões molares álcool/óleo, concentrações de hidróxido de potássio de $0.3,0.5,0.7$ e $1 \%$ em relação a massa do óleo. Tendo em vista tal trabalho, alguns testes preliminares para conhecimento do equipamento foram propostos os testes descritos na Tabela 1. Para uma efetiva avaliação do efeito de ultrassom na unidade utilizada foram realizados ensaios em bancada sem a aplicação de ultrassom, e na unidade semi-piloto com aplicação de ultrassom.

Tabela 1. Delineamento experimental.

\begin{tabular}{clllll}
\hline Reação & $\begin{array}{l}\text { Razão } \\
\text { Molar }\end{array}$ & Temperatura & Catalisador & Vazão & Tempo \\
\hline $\mathbf{1}$ & $9: 1$ & $55^{\circ} \mathrm{C}$ & $0,5 \% \mathrm{KOH}$ & bancada & $60 \mathrm{~min}$ \\
$\mathbf{2}$ & $9: 1$ & $\begin{array}{l}\text { Temperatura } \\
\text { Ambiente }\end{array}$ & $0,5 \% \mathrm{KOH}$ & $800 \mathrm{~mL} \cdot \mathrm{min}^{-1}$ & $60 \mathrm{~min}$ \\
$\mathbf{3}$ & $9: 1$ & $55^{\circ} \mathrm{C}$ & $0,5 \% \mathrm{KOH}$ & $800 \mathrm{~mL} \cdot \mathrm{min}^{-1}$ & $60 \mathrm{~min}$ \\
$\mathbf{4}$ & $9: 1$ & $\begin{array}{l}\text { Temperatura } \\
\text { Ambiente }\end{array}$ & $0 \% \mathrm{KOH}$ & $800 \mathrm{~mL} \cdot \mathrm{min}^{-1}$ & $60 \mathrm{~min}$ \\
$\mathbf{5}$ & $9: 1$ & $55^{\circ} \mathrm{C}$ & $0 \% \mathrm{KOH}$ & $800 \mathrm{~mL} \cdot \mathrm{min}^{-1}$ & $60 \mathrm{~min}$ \\
$\mathbf{6}$ & $9: 1^{*}$ & $55^{\circ} \mathrm{C}$ & $0,5 \% \mathrm{KOH}$ & $400 \mathrm{~mL} \cdot \mathrm{min}^{-1}$ & $16 \mathrm{~min}$ \\
$\mathbf{7}$ & $9: 1^{*}$ & $55^{\circ} \mathrm{C}$ & $0,5 \% \mathrm{KOH}$ & $800 \mathrm{~mL} \cdot \mathrm{min}^{-1}$ & $8 \mathrm{~min}$ \\
\hline
\end{tabular}

* obs.: teste de relação entre o ultrassom e tempo de residência, com vazão máxima e metade da vazão da bomba. 
Com o delineamento experimental, a amostragem da reação foi realizada em diferentes tempos de reação (de 2 a 60 min). Todas as alíquotas foram neutralizadas com uma solução de ácido fosfórico $5 \%$ a fim de parar a reação.

\section{RESULTADO E DISCUSSÃO}

Os ésteres etílicos obtidos nas diferentes condições cinética avaliadas no presente trabalho, após sua purificação, foram preparados para a cromatografia gasosa. Pesou-se aproximadamente 5 mg de cada amostra e diluiu-se em $1 \mathrm{~mL}$ de n-heptano. Após sua injeção no CG, o resultado foi integrado numa curva de calibração. A Figura 5 mostra um perfil cromatográfico obtido da reação 1 (ver Tabela 1) de 2 min e a Figura 6 da mesma reação em 60 min.

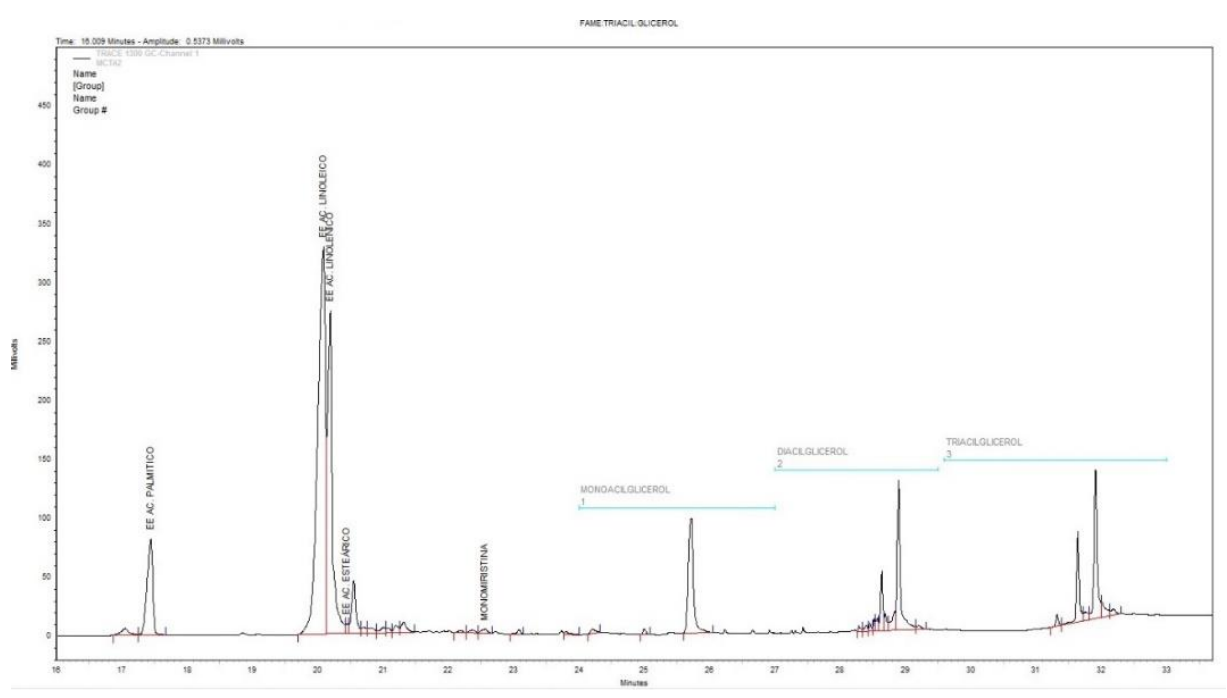

Figura 5. Perfil cromatográfico após 2 min de reação



Figura 6. Perfil cromatográfico após 60 min de reação. 
Num comparativo entre estes dois resultados, observa-se que em 2 min (Figura 5) tem-se uma quantidade significativa de ésteres, porém, observa-se também a presença de MAG (monoacilglicerol), DAG (diacilglicerol) e TAG (triacilglicerol). Em 60 min (Figura 6) tem-se um significativo consumo de MAG (monoacilglicerol), DAG (diacilglicerol) e TAG (triacilglicerol) para ésteres etílicos, pois houve um decréscimo no sinal do detector para esses compostos.

Na Figura 7 é apresentada uma comparação entre os perfis cinéticos obtidos para as diferentes reações. Pode ser observado a partir desta figura que na reação 1 (ver Tabela 1) o primeiro ponto retirado de 2 min apresenta um teor de ésteres totais em torno de $33 \%$ (em massa) na amostra e, conforme a reação avança, cada alíquota retirada e tratada tem o perfil de que a reação continua gradativamente ocorrendo até alcançar um teor de $89 \%$ em ésteres etílicos. Para a reação 2 (Tabela 1), conforme esperado, devido à influência do ultrassom, o primeiro ponto retirado de 2 min, apresenta um teor de éster de $49 \%$ com um pequeno aumento, até o último ponto de $60 \mathrm{~min}$, em que uma conversão de $62 \%$ em teor de éster foi atingida. Na reação 3, o primeiro ponto a 2 min, apresentou um teor de éster de $45 \%$ e este sem manteve praticamente constante ao longo da reação (conversão de 49 \% em teor de éster em 60 min de reação). Comparando-se as reações 2 e 3, temse que para a reação 2 o ultrassom foi mais efetivo em condições de temperatura ambiente quando comparado com reação 3 pré-aquecida a 55 C (Figura 7). Ambas reações ( 2 e 3 ) mostram que não há a necessidade de se prolongar o tempo de reação uma vez que após 15 min de reação a conversão se mantém praticamente constante.



Figura 7. Comparação entre as cinéticas de diferentes condições reacionais.

As reações 4 e 5 (ver Tabela 1), tiveram baixas concentrações em torno de $5 \%$ do seu início ao seu fim. Mostrando assim a necessidade real de um catalisador além do ultrassom (Figura 7). 
Na Figura 8 são apresentados os dados das cinéticas das reações 6 e 7, apresentadas na Tabela 1. Para a reação 6 o primeiro ponto foi alíquotado em $20 \mathrm{~s}$ de reação. Nesta condição foi obtido um teor de éster de $57 \%$, aproximadamente, e para o seu ponto intermediário (8 min) alcançou-se 61 $\%$ no teor de ésteres, e se manteve constante em $62,5 \%$. A reação 7 apresentou o mesmo perfil, porém, o tempo da ação do ultrassom foi menor, devido a maior vazão volumétrica utilizada $(0,8$ L.min $\left.{ }^{-1}\right)$. Para esta condição reacional o primeiro ponto $(20 \mathrm{~s})$ apresentou $49 \%$ no teor de éster e alcançou um valor de aproximadamente $56 \%$ ao final de um tempo de reação de 8 min.

A partir dos resultados obtidos, verifica-se que a vazão volumétrica é uma variável importante neste processo, uma vez que as reações 6 e 7 foram realizadas com a mesma razão molar (etanol/óleo), percentual de catalisador em relação a massa de óleo e temperatura. Sendo que quanto maior o tempo de ação do ultrassom na reação maior o favorecimento na conversão. Ainda, para o mesmo tempo reacional de $20 \mathrm{~s}$ nas diferentes condições reacionais, houve um aumento na conversão (Figura 8).

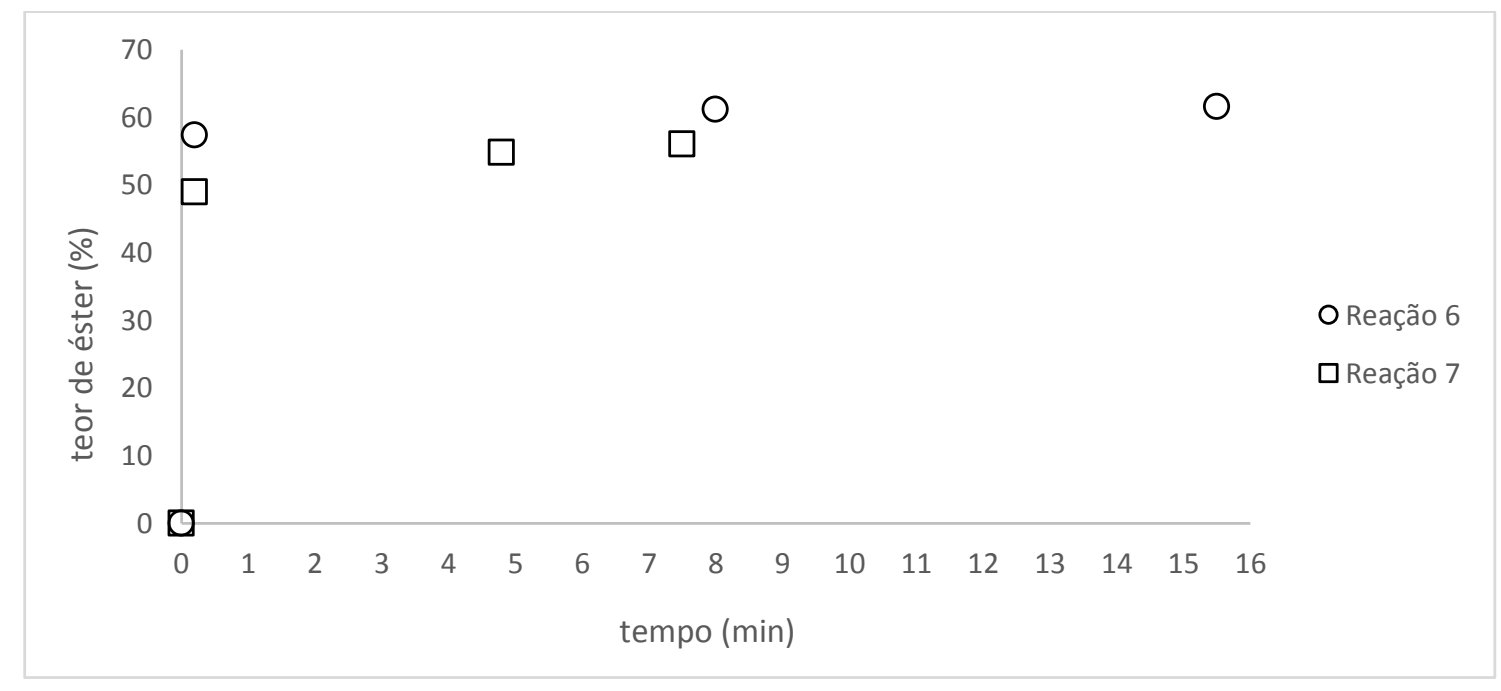

Figura 8. Comparação da reação 6 e 7 do delineamento experimental.

\section{CONCLUSÃO}

A sonólise de óleos vegetais mostrou consideráveis ganhos de tempo em relação à transesterificação alcalina clássica. Os resultados obtidos com os tempos de reação podem ser explicados pela intensa transferência de massa proporcionada pelas condições únicas geradas através da cavitação sonora. Este método apresenta-se como uma potencial rota tecnológica de produção capaz de atender demandas de biodiesel em curtos períodos de tempo. Ajustes quanto ao tipo de reator ultrassônico e o regime de condução do processo, por exemplo vazão volumétrica, podem fazer da sonólise de óleos vegetais uma excelente alternativa para produção de biodiesel 
com gastos energéticos que podem ser inferiores aos gastos envolvidos com o método tradicional com agitação mecânica.

O equipamento utilizado para os experimento se mostrou eficaz na mistura e no funcionamento, tendo uma operação relativamente simples. Vale salientar que ele é um reator semipiloto e necessita de grandes quantidades de reagentes para sua operação, quando comparado com as demandas para ensaios de bancada, e algumas alterações podem ser feitas para melhorar seu desempenho.

A técnica de cromatografia foi satisfatória para monitorar as conversões em ésteres etílicos, sendo uma técnica capaz de prover informações das mais variadas conversões como as observadas neste trabalho.

De uma forma geral, os resultados mostraram que a reação é extremamente rápida quando assistida em ultrassom. Nos instantes inicias ( $2 \mathrm{~min}$ ) a reação alcança altas taxas de conversão e se mantem constante (em equilíbrio) até o final dos experimentos realizados. Isto mostra que não há a necessidade de longos períodos para se obter uma alta conversão. Do ponto de vista de projeto, isto implica na possibilidade de utilização de menores tempos de reação e maiores tempos de residência e na construção de reatores com menores volumes.

\section{REFERÊNCIA BIBLIOGRÁFICA}

BORENSTEIN, D. Análise Da Viabilidade Da Produção De Biodiesel A Partir Da Soja No Brasil. p. 2448-2459, 2008.

História Biodiesel Disponível em <http://www.biodieselbr.com/biodiesel/historia/ biodieselhistoria.htm> Acesso dia 15/05/2013

KNOTHE, G.; GERPEN, J. V.; KRAHL, J.; RAMOS, L. P. Manual de Biodiesel. São Paulo: Editora Edgard Blücher, p. 5-7, 12 , 13, 2006.

PAIVA E. J. M., Estudo Da Produção De Biodiesel A Partir Do Óleo De Babaçu E Etanol Utilizando Transesterificação Alcalina Tradicional Com Agitação Mecânica E Assistida Por Ultrassons, 173 f. Dissertação (Mestrado em Engenharia Química) Escola de Engenharia de Lorena Universidade de São Paulo Lorena 2010

PINTO, A. C., GUARIEIRO, L. L. L., REZENDE, M. J. C., RIBEIRO, N. M., TORRES, E.A., LOPES, W. A., PEREIRA, P. A.P., de ANDRADE, J. B. Biodiesel: na overview. J. Braz. Chem. Soc. V.16, p.1313, 2005

THANH, L. T.; OKITSU, K.; SADANAGA, Y.; TAKENAKA, N. Bioresource Technology Ultrasound-assisted production of biodiesel fuel from vegetable oils in a small scale circulation process. Bioresource Technology, v. 101, n. 2, p. 639-645, 2010. Elsevier Ltd. Disponível em: <http://dx.doi.org/10.1016/j.biortech.2009.08.050>. 